\title{
Awareness: A Study of Knowledge Management Adoption amongst Iranian SMEs
}

\author{
Naser Valaei and Kamarulzaman Ab. Aziz \\ Faculty of Management, Multimedia University, Cyberjaya, Malaysia
}

\begin{abstract}
Nowadays, companies that are unaware of knowledge management $(\mathrm{KM})$ and its concepts are considered illiterate in business context. In order to thrive in this turbulent market, a company must be familiar with all concepts pertaining to its intellectual assets, i.e. KM, KM strategy, KM processes, its knowledge workers and all other activities involved in managing intangible assets. Small and medium-sized enterprises (SMEs) as drivers of economical growth play a major role in prosperity and innovativeness of almost all countries worldwide. In this study, a sample of 63 SMEs in north of Iran is drawn for data analysis. Obstacles and issues regarding $\mathrm{KM}$ are clearly stated and the degree of their awareness toward KM concepts is measured.
\end{abstract}

Keywords: Knowledge management, Awareness, SMEs, Iran

\section{Introduction}

\section{Knowledge Management}

It is evident that the word knowledge management (KM) has been used for diverse activities intended to administer, produce, improve and raise the merit and worthiness of intellectual resources within an organization, and unsurprisingly there exists no unanimity on the meaning and explanation of KM (Haggie and Kingston, 2003). Liebowitz (1999) states that "KM is a mixture of abstracts lent from the knowledge-based systems, software engineering, human resource management and organizational behavior". It engages five processes: to obtain and create the data or information, disseminate and process the acquired information, along with the promulgation of obtained information extracted through the data to those who can act and process it.

\section{Approaches to Knowledge Management}

By applying Earl's (2001), KM can be classified into perspectives. This classification into perspectives is established upon appropriateness to the nature of usage of knowledge within business context which is called "school of KM". Three appropriate schools are classified by Earl as "economic school, organizational school, and strategic school". The economic perspective is concentrated on profit or the monetary view of knowledge within which the purpose is to make use of intellectual or intangible assets. The organizational perspective is concentrated on interrelations of all entities (involving employees as well as top managers) within organization for the purpose of making a knowledge setting.

Knowledge setting refers to an environment or circumstances where the repository of knowledge is available to all entities. The strategic perspective is concentrated on core competencies, merits and advantages with the purpose of determining, exploring and exploiting knowledge capacities.

As cited by Earl, "economic perspective is about managing knowledge as an asset, in which knowledge or intellectual assets consist of patents, copyrights and trademarks". Plenty of approaches are

Copyright (c) 2012 Naser Valaei and Kamarulzaman Ab. Aziz. This is an open access article distributed under the Creative Commons Attribution License unported 3.0, which permits unrestricted use, distribution, and reproduction in any medium, provided that original work is properly cited. Contact author: Naser Valaei E-mail: naservalaei@gmail.com 
available for appraisal of knowledge resources. Fundamentally, the knowledgevalue-added (KVA) is an approach in which the circulated knowledge within business context is viewed from a monetary phase. It means that the knowledge regarding its level of significance and expertise is numerically valued. This perspective towards the knowledge assets permits assigning of revenues in portion to value added by the knowledge along with cost of using that knowledge.

Organizational perspective delineates taking advantage of organizational structure or inter-relations between entities within organization to partake knowledge communication process. It has been examined frequently as knowledge community, which is defined as a group of people with same interest and difficulty regarding knowledge activities. Knowledge communities are formed and planned for peculiar goals and ambitions. Their practices can benefit dynamically external environment as well as internal environment.

\section{Factors Influencing KM Adoption}

There are plenty of factors involved in the effectiveness of $\mathrm{KM}$. We consider these factors by virtue of their importance one by one. First of all, learning as a method or tools may have a critical role in $\mathrm{KM}$ effectiveness and efficiency. Learning is the heart of "knowledge creation process" which is the driver of creativity and innovativeness in the organization. By advancements in technology, the new term of electronic learning (e-learning) has emerged. There are various tools and applications that ease the function of elearning through World Wide Web. Web 2.0 applications can be considered fascinating tools for businesses to manage the process of knowledge creation and sharing.

Organizational culture is another factor influencing the effectiveness of KM. Culture as a unique infrastructural foundation demonstrates a substantial role in the installation and acceptance of knowledge management system (KMS) as well as its success and effectiveness. Further, it determines the degree of knowledge sharing as well as the intensity to participate in this process within organization. "Knowledge friendly culture" is appointed to all entities operating in a company with a profound feeling and desire regarding to all knowledge activities: "acquisition, conversion, application, and protection" (Meso and Smith, 2000). The structure within which the culture shapes itself (i.e. the company or organization) is quite unique which is impossible to be replicated. Therefore, "Knowledge friendly culture" is a strategic asset due to that it cannot be imitated, replaced or replicated. Organizations should have a strategy to cultivate trust among employees thereby encouraging them to have a tendency to practice and participate in all activities pertaining to circulating knowledge in business context.

Organizational structure, the last but not least, as an infrastructural requirement to the skeleton of $\mathrm{KM}$ has a major role in its effectiveness and prosperity. KM needs a structure in which the collaboration between different business units and groups is established at a high level. Organizational infrastructure is not tangible. Each organization has a unique structure that is not similar to other organizations. Davenport et al. (1998) declared that "a well-developed organizational infrastructure can be a source of long lasting competitive advantage". This merit does not result from organizational ranking policies but dynamic mutual action of individuals and teams that make up the hierarchy by assistance of middle managers and front line employees. It could be facile to copy the "organization's hierarchy" or ranking system but it is absolutely cumbersome to imitate the exact characteristic of mutual action happening in the context of business processes in a company. Therefore, organizational infrastructure can be seen as an important asset and it could be identified as a fertilizer for effectiveness of KM. Organizations should flatten the hierarchy to reduce extra bureaucracy, coordinate the tasks without difficulty and 
promulgate the culture of collaboration throughout the organization.

\section{Knowledge Management Process}

The knowledge-based economy is a reality (Halawi et al., 2006). KM is demonstrated as an assembly of concepts, theories as well as activities publicized in this century containing "core competencies, resourcebased theories, balanced scorecard and intellectual assets, total quality management and so forth" (Corrall, 1998). It implies that $\mathrm{KM}$ has a crucial role in activities and processes pertinent to value chain. A prior condition of implementation of $\mathrm{KM}$ is to perceive and develop infrastructure elements needed to bolster the gathering, management and transfer of tacit and explicit organizational knowledge. These elements are processes, people and technology.

Any process that bolsters one of four components of $\mathrm{KM}$ can be seen as a $\mathrm{KM}$ process. Components of $\mathrm{KM}$ are knowledge acquisition, retention, exploitation and protection. KM process is about taking advantage of intellectual capital of individuals for the purpose of realizing an organization's innovating capabilities (Swan et al., 2000). Tiwana (2002) identifies fundamentals of $\mathrm{KM}$ processes as "knowledge acquisition, knowledge sharing and knowledge utilization". He states that technology as a medium must be able to support each stage of KM process. One must notice that technology is merely an enabler which is strongly contingent in the organization context.

Companies can execute five courses of action to be successful in the KM processes:

1.First of all, they have to identify problems and outline set of actions regarding knowledge activities.

2.Establish knowledge crew/worker as cross functional employees who can participate in the process of decision making.

3. Senior and middle level managers must participate in the process.
4.Assist companies to influence their organizational culture to practice knowledge activities.

5. Making knowledge accessible by utilizing various networks and technologies.

\section{Knowledge Management Strategy}

Strategy can be determined as a balance between internal resources (strengths) and the opportunities raised from external setting (Grant, 1991). In other words, strategies surface due to mutual actions of an enterprise with its business setting together with its knowledge workers and all who participate in this process (Nurmi, 1998). Moreover, Barney (1991) states that a course of action is claimed to be a "competitive advantage" at the time when a company develops an appropriate set of actions which is not concurrently being developed by competitors. As stated by Porter (1985), competitive advantage can be considered "the ability to obtain return on investment above the average". Porter (1996) states that the spirit of a strategy is in its activities which are pertinent to carrying out these tasks in a different manner or to do different activities than its rivals. Further, a prolonged and advantageous core competency is identified as the extent to which a company obtains a "superior performance" at the time it designs and develops set of actions which is not simultaneously developed by its rivals and at the time rivals are impotent and hesitant to procreate and are unaware of these set of actions (Barney, 1991). KM activities are believed to be the most recent set of actions in intensifying company's performance (Bell and Jackson, 2001).

Fahey (1996) mentioned that two significant concepts i.e. "knowledge and strategy" are complex having dynamic definitions with many facets. Strategyoriented knowledge consists of plenty of diverse fields, including "competitors, customers, suppliers, technologies, regulations and policies". An organization has the opportunity to observe the current course of actions to find out the way that it could utilize all potential "knowledge assets", or consider to the available and 
core knowledge to pinpoint which course of action will fit the demanded advantages and suitable for its business setting (Halawi et al., 2006). Thus, it is more likely to recognize the linkage between strategy and knowledge regarding the way that the latter and its appropriate administration have the potential to produce "strategic advantage" for an organization.

As stated by Zack (1999), the first step for an enterprise to delineate the connections between "knowledge and strategy" is to precisely express its strategic design and determine what types of intellectual resources are imperative to accomplish the suggested course of action thereby disclosing its strategic knowledge gap. This strategic knowledge gap can be covered by a KM strategy. Tiwana (2000) mentioned that knowledge compels strategy and strategy compels KM. Moreover, he states that without a clearly expressed and well defined linkage between $\mathrm{KM}$ and business strategy, even the world's best KM systems will have a zero value. Strategic business managers and knowledge manages, thus, should notice the significant impact of knowledge in corporate strategy's formulation and business success.

Halawi et al., 2006 state that "KM strategy is the process of creating, codifying, and promulgating tacit and explicit knowledge within an organization/firm, transferring the right information/knowledge to the right persons, in the right place and occasion". The knowledge strategy clarifies the requirements, the path and set of activities to meet the designated goals. It must be mentioned that knowledge strategy isn't identical to KM strategy. Knowledge strategy is a well-practiced course of action that an enterprise hold accountable for all issues regarding $\mathrm{KM}$, to give power to it. According to Civi (2000), a firm's well practiced course of action (i.e. strategy) must reveal its corporate view to those actions which dominated entirely the firm. In addition, competitive/ corporate course of action is required to be as an enabler to KM strategy. For organizations, in order to flourish in exploitation of their knowledge assets, a proper balance between the organization's mission and objectives and its KM strategy should be identified. This suggests that KM strategy should be aligned with corporate strategy. Drew (1999) investigated the way in which the responsible administrators could implement $\mathrm{KM}$ in their strategic activities within organizations. He states the substantial requirement to implement KM in direction of "strategy formulation" which is the setting of vision and mission as well as observing and assessing external and internal environment.

Unfortunately, development of KM has mainly focused on IT in which business strategy is not even concerned (Zack, 1999). It indicates that the integration between KM strategy and business strategy has been missed. The most significant context for leading KM is the firm's course of action. The firm's strategy aids to identify $\mathrm{KM}$ initiatives that bolster its mission and objectives. Snyman and Kruger (2004) declared that "KM strategy should, therefore, not be managed analogous with business strategy, but should be an integral part of business strategy". Zack (1999) proposed that "knowledge assets should be analyzed in connection with their support of business strategy by accomplishing a SWOT analysis".

\section{Knowledge Workers}

The term "knowledge work" or "knowledge worker" is proportionately a new concept initially defined by Peter Drucker (1959). Drucker specified knowledge worker (KW) as those employees that take advantage of their intellectual resources. Then, in the early 1990s, he represented KWs as employees who utilize analytical and theoretical knowledge to facilitate innovation and develop new goods and services. According to Davenport and Prusak (2000), Knowledge workers are assigned to those who produce knowledge or those whose use of knowledge is the most important aspect of their work. They expanded this concept by defining KWs as those educated people or expertise whose work is mostly related to creation, dissemination or application of knowledge. 
Another definition of KWs is given by Horvath (2001) which defines KWs as those who work for a living at the tasks of utilizing or developing knowledge. By virtue of this broad definition, a wide range of tasks can be identified, such as planning, storing, organizing, programming, analysing, researching, distributing, marketing and many other tasks that demand transformation of information. Thus, KWs can be managers, engineers, analysts, accountants, programmers, lawyers and so forth.

\section{Small and Medium Sized Enterprises (SMEs)}

Nowadays, a growing number of nations are experiencing a competitive market rather than a monopolistic market SMEs, as industrial wheels have a substantial role in a country's growth and success (Valaei, 2011). Today, the competitiveness in current economy has shifted from tangible or physical resources to intangible or intellectual resources. Concerns of information systems have changed from managing the information to manage knowledge. Those SMEs that embrace the $\mathrm{KM}$ activities and deploy them within their organizations have an advantage over their competitors. Further, SMEs have a profound contribution to the GDP of a country. In this arena of IT revolution, in order to be competitive, companies take advantage of $\mathrm{KM}$ to manage their expertise and knowledge which contains the most precious asset of the company.

SMEs comprise 90 percent of all enterprises in Iran (Bayati, 2007).In this study, SMEs in Iran are analyzed and the degree of their awareness toward $\mathrm{KM}$ concepts is measured. In Iran, companies with employees between 10 and 49 are regarded as small businesses and companies with employees between 10 and 99 are regarded as SMEs. Iran is extremely dependent on its oil and gas production, and around 82.5 percent of its exports are from this industry. In this globalized market, Iran needs to expand its non-oil exports in order to deal with competition and present itself as an important representative of middle-eastern countries in WTO. Unfortunately, Iranian industrial SMEs contribute less than five percent of non-oil exports but it has great potential in boosting export with enormous scope for growth in the country.

SMEs as wheels of industries have a profound influence on the global economy. It is predicted that the development of SMEs will be the key success factor for next decades throughout the world. All research studies in this context agree with the fact that SMEs have created job opportunities, technological improvement and innovation capacities along with high income. SMEs have a significant contribution to gross domestic product (GDP) and industrial dynamicity. Due to severe global competition and high customer demands for new goods and services, their importance has increased. SMEs are the foundation of developed economies worldwide. They shape the formation of private sector, comprise over 90 percent of enterprises worldwide and constitute 50 to 60 percent of employment. They have a higher contribution in manufacturing industries, and in developing economies; they account for 90 to 95 percent, or more, of all industrial enterprises. They account for 70 to 75 percent of industrial employment and around 50 to 60 percent of industrial output. Additionally, a study conducted by "Ministry of Industries in Iran about the role of industrial SMEs in total exports" indicates that the nation's entire export will increase up to 108 billion dollar by the year 2020/2021. Industrial sector will contribute more than 52 billion dollars. In order to achieve this goal, Iran must have an open-economy; otherwise it would be difficult to reach that goal.

\section{Research Methodology}

For the purpose of collecting primary data for this study, a questionnaire is designed for companies in north of Iran to find out their level of understanding toward KM, technology availability and usage, issues related to $\mathrm{KM}$ and obstacles to implement it. 70 questionnaires were issued of which 63 were accepted for data analysis. Table 1 summarizes the demographic information of Iranian SMEs participated in this study. 
Respondents are categorized based on three industry sectors including manufacturing (67.5\%), service $(6.5 \%)$ and others $(26 \%)$. Most of respondents are chief executive officers (47.6\%). Other executives and managers consist of $36.5 \%$ and $15.9 \%$. Regarding size of company, $14.3 \%$ have below 10 employees; $25.4 \%$ have employees between 10 and 30; $17.5 \%$ have employees between 30 and 50; 23.8\% have employees between 50 and 70; and 19\% have employees between 70 and 99 .
Most of companies participating in this study are registered under Limited (LTD) Co. which stands for $90.5 \%$. $7.9 \%$ of companies are registered under Cooperative company as well as $1.6 \%$ for Limited liability partnership (LLP). Most companies $(66.6 \%)$ have annual sales of below than 10 million dollars. $49.1 \%$ of companies have been in business for 5 to 10 years and $30.1 \%$ of them have more than 20 years of experience.

Table 1: Demographic Information of Iranian SMEs

\begin{tabular}{|l|l|}
\hline Industry sector & $\begin{array}{l}\text { Manufacturing (67.5\%) } \\
\text { Service (6.5\%) } \\
\text { Others (26\%) }\end{array}$ \\
\hline $\begin{array}{l}\text { Position in the } \\
\text { company }\end{array}$ & $\begin{array}{l}\text { CEO (47.6\%) } \\
\text { Other executives (36.5\%) } \\
\text { Managers (15.9\%) }\end{array}$ \\
\hline Number of employees & $\begin{array}{l}\text { Below 10 (14.3\%) } \\
\text { Between 10-30 (25.4\%) } \\
\text { Between 30-50 (17.5\%) } \\
\text { Between 50-70 (23.8\%) } \\
\text { Between 70-99 (19.0\%) }\end{array}$ \\
\hline $\begin{array}{l}\text { Registration status of } \\
\text { company }\end{array}$ & $\begin{array}{l}\text { Limited (LTD) Co. (90.5\%) } \\
\text { Cooperative company (7.9\%) } \\
\text { Limited liability partnership (LLP) (1.6\%) }\end{array}$ \\
\hline Annual sales & $\begin{array}{l}\text { Below 5 million dollars (33.3\%) } \\
\text { Between 5-10 million dollars (33.3\%) } \\
\text { Between 10-15 million dollars (14.3\%) } \\
\text { Between 15-20 million dollars (12.7\%) } \\
\text { More than 20 million dollars (6.3\%) }\end{array}$ \\
\hline $\begin{array}{l}\text { History of the } \\
\text { company }\end{array}$ & $\begin{array}{l}\text { 1-5 years (8\%) years (49.1\%) } \\
\text { 5-10 years (12.8\%) } \\
\text { More than 20 years (30.1\%) }\end{array}$ \\
\hline
\end{tabular}

\section{Knowledge Management Awareness}

Do managers have to be knowledge champions or care for lessons learned and knowledge sharing? Is a KM workshop helpful or should it be a common topic in meetings? Is KM included in annual reports and is it aligned to organizational objectives and goals? How does one settle a placement and an appropriate arrangement between management priorities and KM opportunities? The answer for all these questions is "awareness of KM at management levels". Managers should be aware of KM terminology and its key components. Whereas they are involved in value chain activities (inbound logistics, operation, outbound logistics, marketing and sales and services) (Porter, 1985), they must consider knowledge value chain (KVC) model in their value chain analysis. 
Further, a KM workshop is essential to create interest and stimulate managers and employees to practice it. A KM workshop would induce managers to realize the importance of $\mathrm{KM}$ within their company/ organization. Then, KM should be reflected in regular meetings due to its vital role in organization's life cycle.

To align organizational priorities and $\mathrm{KM}$ opportunities, management should consider learning about KM activities. Top managers should be positive, should consent to be a learning organization and should create an enabling atmosphere for practicing KM within organization. Employees should take advantage of learning opportunities and $\mathrm{KM}$ initiatives should be combined in their job descriptions with proper training.

In the following sections, the result of questions pertaining to Iranian companies' understanding and perceptions toward $\mathrm{KM}$ will be analyzed and categorized in terms of statements asked in questionnaire.
However, a good perception or understanding of $\mathrm{KM}$ definitions and principles is imperative for companies in order to develop their own KM strategy. Each statement is measured based on a seven-level Likert Scale as (0) Don't know/ Not sure, (1) Totally disagree, (2) Disagree, (3) Somehow disagree, (4) Somehow agree, (5) Agree and (6) Totally agree.

Statement 1: "KM is a process of creation, assimilation, retention and utilization of knowledge".

The respondents' degree of agreement/disagreement toward this statement is summarized in table 2 . Surprisingly, most respondents decided to concur with the first statement in which 50.8 percent have chosen "agree" and 12.7 percent for "totally agree". 36.5 percent have chosen "somehow agree". It can be deduced that all the participants have chosen correctly regarding this statement.

Table 2: KM is a Process of Creation, Assimilation, Retention and Utilization of Knowledge

\begin{tabular}{|c|c|c|c|c|c|}
\hline & & Frequency & Percent & Valid Percent & $\begin{array}{c}\text { Cumulative } \\
\text { Percent }\end{array}$ \\
\hline \multirow[t]{4}{*}{ Valid } & Somehow agree & 23 & 36.5 & 36.5 & 36.5 \\
\hline & Agree & 32 & 50.8 & 50.8 & 87.3 \\
\hline & Totally agree & 8 & 12.7 & 12.7 & 100.0 \\
\hline & Total & 63 & 100.0 & 100.0 & \\
\hline
\end{tabular}

Statement 2: "IT is a key part of KM".

Surprisingly, as tabulated in table 3, most respondents (63.5 percent have chosen "agree/ totally agree" and 30.2 percent have chosen "somehow agree") agreed with this statement.

Table 3: IT is a Key Part of KM

\begin{tabular}{|c|c|c|c|c|c|}
\hline & & Frequency & Percent & Valid Percent & $\begin{array}{c}\text { Cumulative } \\
\text { Percent }\end{array}$ \\
\hline \multirow[t]{7}{*}{ Valid } & Don't knowinot sure & 2 & 3.2 & 3.2 & 3.2 \\
\hline & Totally disagree & 1 & 1.6 & 1.6 & 4.8 \\
\hline & Somehow disagree & 1 & 1.6 & 1.6 & 6.3 \\
\hline & Somehow agree & 19 & 30.2 & 30.2 & 36.5 \\
\hline & Agree & 32 & 50.8 & 50.8 & 87.3 \\
\hline & Totally agree & 8 & 12.7 & 12.7 & 100.0 \\
\hline & Total & 63 & 100.0 & 100.0 & \\
\hline
\end{tabular}


Statement 3: "KM is all about the utilization of ICT".

Unsurprisingly, as illustrated in table 4 , most respondents (76.2 percent have consented with this statement by choosing "agree/ totally agree") agreed with this statement.

Table 4: Knowledge Management is all about the Utilization of ICT

\begin{tabular}{|c|c|c|c|c|c|}
\hline & & Frequency & Percent & Valid Percent & $\begin{array}{c}\text { Cumulative } \\
\text { Percent }\end{array}$ \\
\hline \multirow[t]{7}{*}{ Valid } & Don't know/not surc & 8 & 12.7 & 12.7 & 12.7 \\
\hline & Disagree & 1 & 1.6 & 1.6 & 14.3 \\
\hline & Somehow disagree & 6 & 9.5 & 9.5 & 23.8 \\
\hline & Somehow agree & $1 /$ & 21.0 & 21.0 & 50.8 \\
\hline & Agree & 29 & 46.0 & 46.0 & 96.8 \\
\hline & Totally agrce & 2 & 3.2 & 3.2 & 100.0 \\
\hline & Tolial & 63 & 1000 & 1000 & \\
\hline
\end{tabular}

Statement 4: "KM is a type of processimprovement method (for instance, Justin-Time, MBO, and so forth)".

As illustrated in table 5, some of the respondents (31.7 percent have chosen "agree/ totally agree" and 36.5 have chosen "somehow agree") agreed with this statement. Moreover, 27 percent (4.8 percent "disagree", 3.2 percent "totally disagree", and 19 percent "somehow disagree") disagreed with this statement and 4.8 percent have chosen "don't know/ not sure".

Table 5: KM is a Type of Process-improvement Method

\begin{tabular}{|c|c|c|c|c|c|}
\hline & & Frequency & Percent & Valid Percent & $\begin{array}{c}\text { Cumulative } \\
\text { Percent }\end{array}$ \\
\hline \multirow[t]{8}{*}{ Valid } & Don't knowinot sure & 3 & 4.8 & 4.8 & 4.8 \\
\hline & Totally disagree & 2 & 3.2 & 3.2 & 7.9 \\
\hline & Disagree & 3 & 4.8 & 4.8 & 12.7 \\
\hline & Somehow disagree & 12 & 19.0 & 19.0 & 31.7 \\
\hline & Somehow agree & 23 & 36.5 & 36.5 & 68.3 \\
\hline & Agree & 13 & 20.6 & 20.6 & 88.9 \\
\hline & Totally agree & 7 & 11.1 & 11.1 & 100.0 \\
\hline & Total & 63 & 100.0 & 100.0 & \\
\hline
\end{tabular}

Statement 5: "KM is a new marketing strategy".

As shown in table 6, some respondents (31.7 percent have chosen "agree/ totally agree" and 30.2 have chosen "somehow agree") agreed with this statement. Moreover, 38 percent (9.5 percent "disagree", 7.9 percent "totally disagree" and 20.6 percent "somehow disagree") disagreed with this statement. 
Table 6: Knowledge Management is a New Marketing Strategy

\begin{tabular}{|c|c|c|c|c|c|}
\hline & & Frequency & Percent & Valid Percent & $\begin{array}{c}\text { Cumulative } \\
\text { Percent }\end{array}$ \\
\hline \multirow[t]{7}{*}{ Valid } & Totally disagree & 5 & 7.9 & 7.9 & 7.9 \\
\hline & Disagree & 6 & 9.5 & 9.5 & 17.5 \\
\hline & Somehow disagree & 13 & 20.6 & 20.6 & 38.1 \\
\hline & Somehow agree & 19 & 30.2 & 30.2 & 68.3 \\
\hline & Agree & 13 & 20.6 & 20.6 & 88.9 \\
\hline & Totally agree & 7 & 11.1 & 11.1 & 100.0 \\
\hline & Total & 63 & 100.0 & 100.0 & \\
\hline
\end{tabular}

Statement 6: "KM is the management of information, knowledge and experience accessible to a company".

Surprisingly, as tabulated in table 7, most respondents (58.7 percent have chosen "agree/ totally agree" and 27 percent have chosen "somehow agree") agreed with this statement which is precisely what knowledge management is about in order to obtain a competitive advantage. A few respondents disagreed and some of them (28.6 percent) chose "somehow disagree".

Table 7: Knowledge Management is the Management of Information, Knowledge and Experience Accessible to a Company

\begin{tabular}{|c|c|c|c|c|c|}
\hline & & Frequency & Percent & Valid Percent & $\begin{array}{c}\text { Cumulative } \\
\text { Percent }\end{array}$ \\
\hline \multirow[t]{6}{*}{ Valid } & Don't knowinot sure & 2 & 3.2 & 3.2 & 3.2 \\
\hline & Disagree & 6 & 9.5 & 9.5 & 12.7 \\
\hline & Somehow disagree & 18 & 28.6 & 28.6 & 41.3 \\
\hline & Somehow agree & 17 & 27.0 & 27.0 & 68.3 \\
\hline & Agree & 20 & 31.7 & 31.7 & 100.0 \\
\hline & Total & 63 & 100.0 & 100.0 & \\
\hline
\end{tabular}

Statement 7: "KM is a training program that all managers must participate".

As illustrated in table 8, some respondents (11.1 percent have chosen "agree" and 34.9 have chosen "somehow agree") agreed with this statement. Moreover, 52.3 percent (9.5 percent "disagree", 11.1 percent "totally disagree" and 31.7 percent "somehow disagree") disagreed with this statement.

Table 8: KM is a Training Programme that all Managers Must Participate

\begin{tabular}{|c|c|c|c|c|c|}
\hline & & Frequency & Percent & Valid Percent & $\begin{array}{l}\text { Cumulative } \\
\text { Percent }\end{array}$ \\
\hline \multirow[t]{7}{*}{ Valid } & Don't knowinot sure & 1 & 1.6 & 1.6 & 1.6 \\
\hline & Totally disagree & 7 & 11.1 & 11.1 & 12.7 \\
\hline & Disagree & 6 & 9.5 & 9.5 & 22.2 \\
\hline & Somehow disagree & 20 & 31.7 & 31.7 & 54.0 \\
\hline & Somehow agree & 22 & 34.9 & 34.9 & 88.9 \\
\hline & Agree & 7 & 11.1 & 11.1 & 100.0 \\
\hline & Total & 63 & 100.0 & 100.0 & \\
\hline
\end{tabular}


Statement 8: "KM is a theory developed by an academician".

Surprisingly, as shown in table 9, most respondents (55.6 percent have chosen “disagree/totally disagree" and 20.6 percent have chosen "somehow disagree") disagreed with this statement. Only 14.3 percent (4.8 percent "agree", 9.5 percent "totally agree") agreed with this statement.

Table 9: KM is a Theory Developed by an Academician

\begin{tabular}{|l|r|r|r|r|}
\hline & Frequency & Percent & Valid Percent & $\begin{array}{c}\text { Cumulative } \\
\text { Percent }\end{array}$ \\
\hline Valid $\quad$ Don't know/not sure & 6 & 9.5 & 9.5 & 9.5 \\
& 19 & 30.2 & 30.2 & 39.7 \\
Totally disagree & 16 & 25.4 & 25.4 & 65.1 \\
Disagree & 13 & 20.6 & 20.6 & 85.7 \\
Somehow disagree & 6 & 9.5 & 9.5 & 95.2 \\
Somehow agree & 3 & 4.8 & 4.8 & 100.0 \\
Agree & 63 & 100.0 & 100.0 & \\
Total & & & \\
\hline
\end{tabular}

Statement 9: "KM is a management trend or fad".

As illustrated in table 10, all respondents (34.9 percent have chosen "totally disagree", 23.8 percent "disagree" and 28.6 percent "somehow disagree"), except one, have disagreed with this statement. Furthermore, 11.1 percent of respondents have chosen "don't know/ not sure".

Table 10: KM is a Management Trend or Fad

\begin{tabular}{|c|c|c|c|c|c|}
\hline & & Frequency & Percent & Valid Percent & $\begin{array}{l}\text { Cumulative } \\
\text { Percent }\end{array}$ \\
\hline \multirow[t]{6}{*}{ Valid } & Don't knowinot sure & 7 & 11.1 & 11.1 & 11.1 \\
\hline & Totally disagree & 22 & 34.9 & 34.9 & 46.0 \\
\hline & Disagree & 15 & 23.8 & 23.8 & 69.8 \\
\hline & Somehow disagree & 18 & 28.6 & 28.6 & 98.4 \\
\hline & Agree & 1 & 1.6 & 1.6 & 100.0 \\
\hline & Total & 63 & 100.0 & 100.0 & \\
\hline
\end{tabular}

In addition to frequency analysis, the descriptive analysis regarding each question with mean, standard deviation is illustrated in table 11. For instance, first statement (KM is a process of creation, assimilation, retention and utilization of knowledge) obtained the highest mean of 4.76, since all respondents agreed firmly with this statement. 
Table 11: Descriptive Statistics of KM Awareness

\begin{tabular}{|c|c|c|c|}
\hline & $\mathrm{N}$ & Mean & Std. Deviation \\
\hline $\begin{array}{l}\text { Knowledge management is a process of creation, } \\
\text { assimilation, retention and utilization of knowledge. } \\
\text { Information Technology is a key part of KM. } \\
\text { Knowledge management is all about the utilization of ICT. } \\
\mathrm{KM} \text { is a type of process-improvement method (for instance, } \\
\text { Just-in-Time, MBO, and so forth.) } \\
\text { Knowledge management is a new marketing strategy. } \\
\text { KM is the management of the information, knowledge and } \\
\text { experience accessible to a company. } \\
\text { KM is a training programme that all managers must } \\
\text { participate. } \\
\text { KM is a theory developed by an academician. } \\
\text { KM is a management trend or fad. } \\
\text { Valid } \mathrm{N} \text { (listwise) }\end{array}$ & $\begin{array}{l}63 \\
63 \\
63 \\
63 \\
63 \\
63 \\
63 \\
63 \\
63 \\
63\end{array}$ & $\begin{array}{l}3.79 \\
3.71 \\
3.21 \\
2.05 \\
1.76\end{array}$ & $\begin{array}{r}.665 \\
1.174 \\
1.676 \\
1.446 \\
1.393 \\
1.197 \\
1.207 \\
1.313 \\
1.088\end{array}$ \\
\hline
\end{tabular}

\section{Deficiencies Caused within Companies Due to Lack of KM Approach}

Some difficulties occurred amongst SMEs due to lack of a KM approach. For instance, $47.6 \%$ of SMEs mentioned that just one or two key employees had the required knowledge about particular project or business process and when these persons left, the company had difficulties in retaining back the knowledge about the project or the process. $36.5 \%$ of respondents mentioned that they were unable to obtain information demanded because the person in charge or the required data was not available at the right time. $41.3 \%$ agreed with the statement that a decision making process had to be put off to a later time due to inaccessibility of persons in charge. $36.5 \%$ of respondents chose the statement that there were unaware of their colleagues' projects. Finally, 19\% agreed that every project was regarded as a new project and all processes involved in a new project had to be initiated from scratch.

\section{Obstacles in Adopting KM}

Respondents were asked about the obstacles in adopting $\mathrm{KM}$ in their companies. $47.6 \%$ have chosen that "lack of understanding of $\mathrm{KM}$ and its benefits" was a restrain in adopting $\mathrm{KM}$. $25.4 \%$ have chosen difficulties in "determining what kind of knowledge to be managed and making it available" as an obstacle. Overcoming technological limitations, lack of technology expertise, lack of technology resources, lack of training, financial limitations, lack of employee's participation, lack of trust and lack of rewards for knowledge sharing were chosen as difficulties and restraints with " $19 \%, 49.2 \%, 11.1 \%, 57.1 \%, 20.6 \%, 38.1 \%$, $46 \%$, and $22.2 \%$ respectively". $55.6 \%$ of respondents mentioned that employees were not willing to share knowledge. 6.3\% mentioned that $\mathrm{KM}$ is not relevant to company's goals. $3.2 \%$ decided to choose that KM costs are not justifiable compared to its potential benefits. 14.3 mentioned that $\mathrm{KM}$ benefits are not significant. $11.1 \%$ stated that $\mathrm{KM}$ implementation is time consuming. And finally 1.6\% declared that $\mathrm{KM}$ is too expensive.

\section{KM Evolution in Iranian Companies}

While businesses are utilizing basic technologies such as Email and database, these technologies will stimulate 
employees to perceive the merits of $\mathrm{KM}$, thus, $\mathrm{KM}$ awareness will be shaped in this stage by considering the "Time" parameter. With employees' thirst to deploy KM activities, the company moves to a new stage which is called KM 1.0. Likewise, the parameter of time is required to quench the thirst of employees who are likely to be dissatisfied with existing technologies (web 1.0 technologies). Therefore, the concept of $\mathrm{KM}$ is meaningful when the company utilizes "Web 2.0 technologies (blogs, wikis, social bookmarking and so forth.)" and by considering the dynamic effect of "Time" parameter, the KM 1.0 moves to a new stage which is called KM 2.0 i.e. the utilization of Web2.0 technologies.

Indeed, passing through the traditional technology to Web 2.0 shifts the company/organization from a controlled and private environment to a public and collaborative setting. The future of $\mathrm{KM}$ and KMS will be fascinating with emergence of Web 3.0 and Web 4.0 in which it would be called KM 3.0 and KM 4.0. Likewise, it requires the parameter of "Time" to shift the organization from KM 2.0 to KM 3.0 and so forth. It should be noted that the crucial role of government in developing policies, foundation and infrastructural technology support is inevitable to pave the way of $\mathrm{KM}$ adoption. Regarding these discussions, Iranian companies are situated between traditional technological stage and web 1.0 stage of $\mathrm{KM}$ and again it requires the parameter of time to enter a new era of KM.

\section{Conclusion}

This study investigates the level of KM awareness amongst Iranian SMEs. Executives were asked nine questions about their understanding of KM. KM awareness is not new amongst Iranian SMEs, considering the fact that principles of KM have been unconsciously practiced by SMEs over and over. Nowadays, the major differences of $\mathrm{KM}$ are the changed environment as well as the technological advancements and tools. Respondents were asked about their IT solutions within their companies and most of them answered that they at least have access to E-mail, Internet and some of them have implemented Intranet as well as databases. Thus, it can be inferred that they are not computer illiterate.

Regarding $\mathrm{KM}$ understanding and perceptions, based on findings in data analysis, most respondents agree that $\mathrm{KM}$ is a process of creation, assimilation, retention and utilization of knowledge. They also concur with the statement that information technology is a key part of $\mathrm{KM}$. In addition, they disagreed that $\mathrm{KM}$ is a management fad or theory developed by an academician. Therefore, it can be concluded that the level of KM awareness amongst Iranian SMEs is medium in which some companies understand the principles of KM but they observe some obstacles and difficulties in pursuing a KM approach. Obstacles in $\mathrm{KM}$ adoption have been identified as "lack of understanding of KM and its benefits, lack of training, lack of employee's participation, lack of trust, lack of rewards for knowledge sharing as well as unwillingness to share knowledge".

\section{Recommendations}

KM will facilitate the process of problem solving and it has a direct relationship with the company's efficiency. Moreover, lack of fundamental communication systems as well as information systems can cause businesses to be uninformed about business environment. Some respondents mentioned that the Internet speed is low in the region. In addition, some of them declared that knowledge sharing is perceived as a wrong business activity. All these aforementioned issues emphasize the government role in supporting and providing assistance to companies pursuing KM. For instance, since high speed broadband is illegal in Iran due to some political issues, policy makers, as an initiative for implementing $\mathrm{KM}$, should provide high speed Internet as well as technological supports to companies. The government can urge a competitive environment in which information is easily circulated among businesses and competitors. To do so, training programs are necessary for executives to learn about the merits of $\mathrm{KM}$ thereby applying its principles within their organization. 


\section{References}

Barney, J. (1991). “Firm's Resources and Sustained Competitive Advantage," Journal of Management, 17(1), 99-120.

Barney, J. (1997). Gaining and Sustaining Competitive Advantage, Addison-Wesley, Reading, MA.

Bayati, A. \& Taghavi, A. (2007). "The Impacts of Acquiring ISO 9000 Certification on the Performance of Smes in Tehran," the TQM Magazine, 19(2), 140-149.

Beckman, T. J. (1999). The Current State of Knowledge Management, in Liebowitz, J. (ED), Knowledge Management Handbook, CRC Press, New York, NY.

Civi, E. (2000). “Knowledge Management as a Competitive Asset: A Review," Marketing Intelligence and Planning, 18(4), 166-174.

Corral, S. (1998). "Knowledge Management: are we in the Knowledge Management Business?," Ariadne, Vol. 18, [Online], [Retrieved December 10, 2010], Available at: Http:/ / Www.Ariadne.Ac.Uk/ Issue18/ Kno wledge-Mgt.

Davenport, T. H., De Long, D. W. \& Beers, M. C. (1998). "Successful Knowledge Management Projects," Sloan Management Review, Winter, Pp.43-57.

Davenport, T. H. \& Prusak, L. (2000).Working Knowledge: How Organizations Manage What they Know, Boston: Harvard Business School Press.

De Tienne, K. B. \& Jackson, L. A. (2001). "Knowledge Management: Understanding Theory and Developing Strategy," Competitive Review, 11(1), 1-11.

Drew, S. (1999). "Building Knowledge Management into Strategy, Making Sense of New Perspective," Long Range Planning, 31(1), 130-136.

Drucker, P. F. (1959). 'Landmarks of Tomorrow,' Harper, New York, NY.
Earl, M. J. (2001). “Knowledge Management Strategies: Toward a Taxonomy," Journal of Management Information Systems, 18(1), 215-233.

Fahey, L. (1996). 'Putting Knowledge into Strategy,' Presentation at the Ernst and Yung Managing the Knowledge of the Organization Conference, Phoneix, AZ.

Grant, R. M. (1991). 'The Resource Based Theory of Competitive Advantage, Implications for Strategy Formulation,' California Management Review, 33(3), 114135.

Haggie, K. \& Kingston, J. (2003). "Choosing Your Knowledge Management Strategy," Journal of Knowledge Management Practice, June, Pp.1-24.

Halawi, L. A., Mccarthy, R. V. \& Aronson, J. E. (2006). "Knowledge Management and the Competitive Strategy of the Firm," the Learning Organization, 13(4), 384-397.

Horvath, L. (2001). "Collaboration: the Key to Value Creation in Supply Chain Management," Supply Chain Management: an International Journal, 6(5), 205-207.

Meso, P. \& Smith, R. (2000). "A ResourceBased View of Organizational Knowledge Management Systems," Journal of Knowledge Management, 4(3), 224-238.

Nurmi, R. (1998). Knowledge Intensive Firms, Business Horizons, May-June, Pp. 2632.

Porter, M. E. (1985). Competitive Advantage, the Free Press, New York, NY.

Porter, M. E. (1996). "What Is Strategy," Harvard Business Review, 74(6), 61-79.

Snyman, R. \& Kruger, C. J. (2004). "The Interdependency Between Knowledge Management and Strategic Knowledge Management," Journal of Knowledge Management, 8(1), 5-19.

Swan, J., Newell, S. \& Robertson, M. (2000). "The Diffusions, Design, and Social Shaping of Production Management Information 
Systems in Europe," Information Technology and People, 13(1), 27-45.

Tiwana, A. (2000). "The Knowledge Management Toolkit: Practical Techniques for Building a Knowledge Management System," Prentice Hall, Upper Saddle River NJ.

Tiwana, A. (2002). The Knowledge Management Toolkit, Prentice Hall, Englewood Cliffs, NJ.

Valaei, N. (2011). 'Knowledge Management Awareness and Utilization: A Study of SMES in Amol, Iran,' a Dissertation for Master of Business Administration of Multimedia University.

Zack, M. H. (1999). "Developing a Knowledge Strategy," California Management Review, 41(3), 125-146. 